[3] Düzce E. SS Ölçeğinin Türkçe Geçerlilik\&Güvenilirliği. Trakya FTR Uzmanlık Tezi 2017.

Disclosure of Interest: None declared

DOI: 10.1136/annrheumdis-2018-eular.3603

\section{AB0343 MYOCARDIAL INVOLVEMENT IN PATIENTS WITH RHEUMATOID ARTHRITIS EVALUATED BY TWO- DIMENSIONAL SPECKLE TRACKING ECHOCARDIOGRAPHY BEFORE AND AFTER 18 MONTHS OF TREATMENT WITH ANTI-TNF DRUGS}

F. Atzeni $^{1}$, L. Gianturco ${ }^{2}$, L. Boccassini ${ }^{3}$, P. Sarzi-Puttini ${ }^{3}$, M. Turiel ${ }^{4}$. ${ }^{1}$ Rheumatology Unit, University of Messina, Messina: ${ }^{2}$ Cardiology Unit, "Beato Matteo" Hospital, GSD Hospitals, Vigevano (PV); ${ }^{3}$ Rheumatology Unit, L. Sacco University Hospital; ${ }^{4}$ Cardiology Unit, IRCCS, Galeazzi Orthopedic Institute, Milan, Italy

Background: Cardiovascular (CV) mortality and morbidity is increased in rheumatoid arthritis (RA). Studies found a more than two- three-fold higher prevalence of ischaemic heart disease in RA patients compared to controls. However, a number of studies indicate that RA is also associated with various non-atherosclerotic CV manifestations. The inflammatory processes in RA may affect different structures of the heart: the most characteristic lesions are conduction defects, but othe less frequent manifestations are pericarditis, cardiomyopathy and valve disease. Objectives: The aim of this study was to evaluate left ventricular myocardial function with two-dimensional speckle tracking echocardiography (STE), in addition to conventional Doppler and tissue Doppler echocardiography, in order to detect subclinical left ventricular myocardial dysfunction in patients with RA.

Methods: The study involved 30 outpatients who fulfilled the 2010 ACR/EULAR criteria for RA (11 males and 19 females; mean age $54.63 \pm 9.36$ years, median disease duration 2 years), at baseline at after 18 months of treatment with antiTNF drugs and 30 healthy controls matched in terms of age, gender and other anthropometric characteristics. All patients underwent a complete physical examination and routine laboratory analysis. CV risk profiles were assessed by means of standard ECG, conventional and stress trans-thoracic echocardography with the measurement of CFR, carotid ultrasonography and pulse wave velocity (PWV). Two-dimensional echocardiographic images were obtained using the apical 4-chamber view at a high frame rate of 70-80 frames/s, and three cardiac cycles were stored in cine-loop format for off-line analysis using commercially available QLAB 9 software (Philips Medical System, USA) in order to assess global longitudinal strain (GLS)

Results: None of the patients showed any signs or symptoms of CV disease, pulmonary involvement, or any other complication. The results of the speckle track ing analysis were significantly different between the two groups, with GLS being significantly lower in the RA patients compared to healthy controls (GLS\%: 18.51 \pm 9.63 vs $20.23 \pm 2.71 ; \mathrm{p}<0.05$ ). Right and left PWV (PWV right, $\mathrm{m} / \mathrm{sec}: 7.52 \pm 1.64$ vs $6.85 \pm 2.02 ; \mathrm{p}=0.06$ and $P W V$ left, $\mathrm{m} / \mathrm{sec}$ : $7.56 \pm 1.60$ vs $6.88 \pm 2.11 ; \mathrm{p}=0.07$ ) and right and left coronary intima media thickness (cIMT) (cIMT right mm: $0.90 \pm 0.22$ vs $0.75 \pm 0.13 ; \mathrm{p}<0.05$ and cIMT left, mm: median $0.89 \pm 0.18$ vs $0.75 \pm 0.09$; $\mathrm{p}<0.05$ ) values were all higher in the RA patients and the differences of cIMT were statistically significant. Furthermore, a significant improvement in GLS in RA patients at 18 months of anti-TNF treatment was observed (GLS\%: $18.51 \pm 9.63 \mathrm{vs}$ $19.09 \pm 9.72 p<0.01$ )

Conclusions: GLS measured by means of speckle tracking echocardiography was impaired in RA patients in the absence of any clinical evidence of CV disease and echocardiographic evaluations negative. This data suggests an early myocardial alteration.

\section{REFERENCE:}

[1] Baktir AO, Sarli B, Cebicci MA, et al. Preclinical impairment of myocardial function in rheumatoid arthritis patients. Detection of myocardial strain by speckle tracking echocardiography. Herz 2015;40(4):669-74.

Disclosure of Interest: None declared

DOI: 10.1136/annrheumdis-2018-eular.6192
$\mathrm{AB} 0344$

DOES THE PRESENCE OF ILD INFLUENCE THE CHOICE OF DMARD AND BIOLOGIC THERAPY IN RHEUMATOID ARTHRITIS?

F. Coath ${ }^{1}$, S. Siddiqui ${ }^{1}$, A. Himashi ${ }^{2}$, A. Bharadwaj ${ }^{3}$, S. Dubey ${ }^{2}$, F. Hayes ${ }^{1}$,

G. Koduri $1^{1} .{ }^{1}$ Rheumatology, Southend University Hospital, Westcliff-On-Sea;

${ }^{2}$ Rheumatology, University Hospital Coventry and Warwickshire, Coventry,

${ }^{3}$ Rheumatology, Basildon University Hospital, Basildon, UK

Background: Interstitial lung disease (ILD) is a progressive fibrotic disease of the lung parenchyma. It is the only complication of rheumatoid arthritis (RA) reported to be increasing, accounting for around $7 \%$ of all RA deaths. ${ }^{1}$ Prognosis of patients with RA-ILD is reported to be poor, with usual interstitial pneumonia (UIP) being the predominant pattern associated with poor survival. ${ }^{2}$ It is a challenge to determine specific pattern of ILD and formulate an appropriate treatment plan to achieve stabilisation. Early use of Methotrexate (MTX) and biologics in RA has improved outcomes and quality of life. However, this causes difficulty when RA patients develop ILD. There are reports of ILD with biologics and DMARDs, although it is difficult to establish a causal relationship or if an exacerbation of preexisting ILD. There are no evidence based guidelines regarding introducing biologics in such patients and clinicians face a dilemma as to whether they should be denied.

Objectives: The aim of this retrospective study is to:

- Check the overall management of RA and ILD.

- Examine whether ILD diagnosis influences treatment of RA.

Methods: We reviewed 37 patients with RA-ILD from 3 hospitals (2001-2017) We collected data on demographics, clinical, Pulmonary function tests, imaging, time from diagnosis to treatment and outcomes.

Results: The majority developed ILD after RA except for 3 patients. Mean age of onset of RA was 67 years, $22(60 \%)$ were female. $32(87 \%)$ were RF or ACPA positive, 25 (68\%) patients smoked. 29 (78\%) patients had baseline PFTs. HRCT showed 13 had NSIP, 20 UIP and 4 were unclassified. Following the diagnosis of ILD, MTX was stopped in 16 patients, reduced in 3 and unchanged in 2. Leflunomide was stopped in 4 and SLZ stopped in 4 , of which 1 had definite alveolitis. Infliximab was stopped in 2 patients.

Specific Treatment for ILD: 12 patients received Rituximab, of those 8 were for ILD and 4 for RA. 4 Patients continued Anti-TNF. 26 patients received steroids, 4 received MMF and 2 Cyclophosphamide. 2 received Abatacept for ILD with active RA and one received Etanercept. 3 were on Carbocysteine, 2 on NAC and 3 on oxygen.

Outcomes: 20 ILD patients were stable and $8(21 \%)$ progressed and died despite treatment. RA disease activity was low to moderate in 23 patients. RA progressed in 8 patients and 1 who received Etanercept was in remission. MTX was stopped in the majority of patients. Steroids were the commonest treatment for RA in the presence of ILD. Rituximab was the drug of choice for RA with severe ILD, followed by MMF and Cyclophosphamide. DMARDs such as HCQ, Leflunomide and SLZ were used for RA in milder ILD and biologics were generally avoided.

Conclusions: There appears to be significant variation in the treatment of RA in the presence of ILD. However Rituximab seems to be the prefered option for severe ILD. There is a need for stratified and standardised guidance for management of RA-ILD.

\section{REFERENCES:}

[1] Bongartz T, Nannini C, Medina-Velasquez YF, et al. Incidence and mortality of interstitial lung disease in rheumatoid arthritis: a population-based study. Arthritis Rheum 2010;62:1583-1591.

[2] Solomon JJ, Ryu JH, Tazelaar HD, et al. Fibrosing interstitial pneumonia predicts survival in patients with rheumatoid arthritis-associated interstitial lung disease (RA-ILD). Respir Med 2013;107:1247-1252.

Disclosure of Interest: None declared DOI: 10.1136/annrheumdis-2018-eular.6990

\section{$\mathrm{AB} 0345$ DOES IRON DEFICIENCY CONTRIBUTE TO FATIGUE OF PATIENTS WITH RHEUMATOID ARTHRITIS WITHOUT ANAEMIA?}

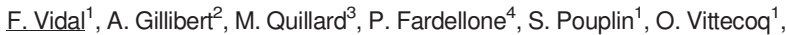
T. Lequerré ${ }^{1} .{ }^{1}$ Rheumatology; ${ }^{2}$ Biostatistics; ${ }^{3}$ Biochemistry, Rouen University Hospital, Rouen; ${ }^{4}$ Rheumatology, Amiens University Hospital, Amiens, France

Background: Iron deficiency (ID) without anaemia is a cause of fatigue, which is itself a recurring complaint of patients with rheumatoid arthritis (RA).

Objectives: The objective of the study was to determine the prevalence of ID in patients with RA without anaemia and to analyse the relationship between ID with fatigue, disease activity and depression. 